\title{
Safety Evaluation of Quayside Container Crane based on Stress Test
}

\author{
Jun Qiu ${ }^{1, *}$, Zheng-qiu Huang ${ }^{1}$, Li-xin Ren ${ }^{1}$, Yao-ting Tong ${ }^{1}$ \\ ${ }^{1}$ Shanghai Institute of Special Equipment Inspection and Technical Research, Shanghai, China
}

\begin{abstract}
Due to the long service life of a quayside container crane in an enterprise, there is slight corrosion on the surface of metal structure, which has potential safety hazard. In order to master the technical condition of the metal structure of the crane, the stress distribution and change information of the crane are obtained by dynamic and static stress testing and non-destructive testing. According to the analysis and test results, the safety assessment of the whole machine is completed and reasonable management suggestions are put forward.
\end{abstract}

\section{Introduction}

Quayside container crane is the main equipment for loading and unloading containers between container ship and wharf front. Its loading and unloading capacity and speed directly determine the productivity of wharf operation. With the continuous growth of port container throughput and the vigorous development of large-scale container ships, the technology of quayside bridge is constantly updated, and the content of science and technology is getting higher and higher. It is developing towards large-scale, high-speed, automatic and intelligent, as well as high reliability and high life.

A quayside container crane has been in service for many years in an enterprise. It has a high frequency of use, a high working level, and is vulnerable to corrosion at the edge of the Yangtze River, and there is a hidden danger of safety. The above unfavorable conditions have different degrees of influence on the safety and reliability of crane steel structure, and the risk of safe operation of equipment is also increased. In this paper, the static and dynamic stress tests ${ }^{[1]}$, the height difference of trolley track in the same section and the nondestructive testing of the main welds are carried out, and the safety evaluation of the whole machine is finally completed, and whether the crane meets the safety requirements of continuing service is further determined, and the improvement scheme is put forward according to the test results[1].

\section{Quayside container crane}

The mechanism of quayside container crane is mainly composed of walking mechanism, lifting mechanism, trolley running mechanism and pitching mechanism. The main technical parameters are rated lifting weight, lifting speed, lifting height, running speed of large trolley, front extension, rear extension and so on.

\section{Static stress test of main metal structures}

According to the evaluation goal, the corresponding test conditions are designed, and the dangerous stress area (including uniform high stress zone, stress concentration zone and elastic yield zone) of crane is tested by stress-strain measuring instrument ${ }^{[2]}$, and the stress distribution and change information are obtained[2]. The distribution of stress test points is shown in figure 1. Test conditions: 1 , no load condition: the instrument data of each position are recorded after the trolley is kept stable at the land side leg, $9 \#$ test point, 8 \# test point, 5 \# test point and 1 \# test point respectively under no load condition. 2, rated load condition: the instrument data of each position are recorded after the trolley is kept stable in the position of land side leg, 9 \# test point, 8 \# test point, 5 \# test point and 1 \# test point under the condition of forehead load. The test results are shown in Table 1. It can be seen from the table that the maximum stress value of the main part of the steel structure is near the middle of the front beam, and when the rated load is at 1 \# position, the maximum stress value is $118 \mathrm{Mpa}$. 


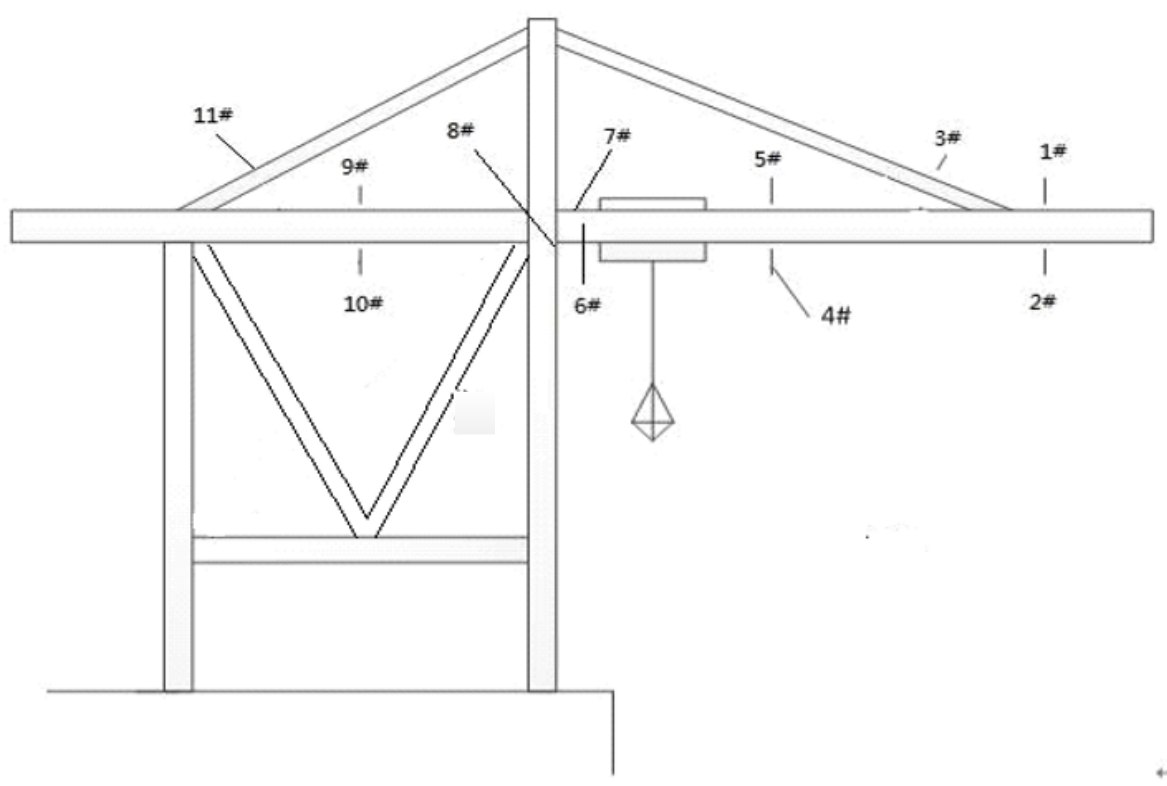

Fig.1 Distribution map of stress measuring points

Table 1 Static stress test result unit: Mpa

\begin{tabular}{|c|c|c|c|}
\hline $\begin{array}{c}\text { Measuring point } \\
\text { number }\end{array}$ & $\begin{array}{c}\text { No-load working } \\
\text { condition }\end{array}$ & $\begin{array}{c}\text { Rated load working } \\
\text { condition }\end{array}$ & Measuring point position \\
\hline 1 & 27 & 107 & The farthest upper cover plate of left front \\
beam
\end{tabular}

\section{Dynamic stress measurement of main metal structures}

One of the working cycles of quayside container cranes is that the rated load rises from the ground between the sea side track and the land side track to the maximum height (brake once)-to the maximum working back extension (brake once)-to the close to the ground brake once)-and then to the maximum height-and to the maximum working front extension (brake once)-falling to near sea level (brake once)-and then rising to the maximum height-running to the ground. According to the above working cycle record and save the dynamic data of the continuous operation of the quayside container crane, the strain-time history of each measuring point is obtained, and then the strain signal is transformed into the corresponding stress value, and the stress-time process is obtained, as shown in figure 2[3]. The selection of measuring points is based on the principle that both the measuring points with large static stress values and the main metal structures are covered, so the test results are shown in Table 2. The results show that the stress measuring points of 4 \# and 5 \# positions in the middle of the front beam bear greater alternating stress and the strain amplitude varies greatly. 


\section{$10^{2}$}

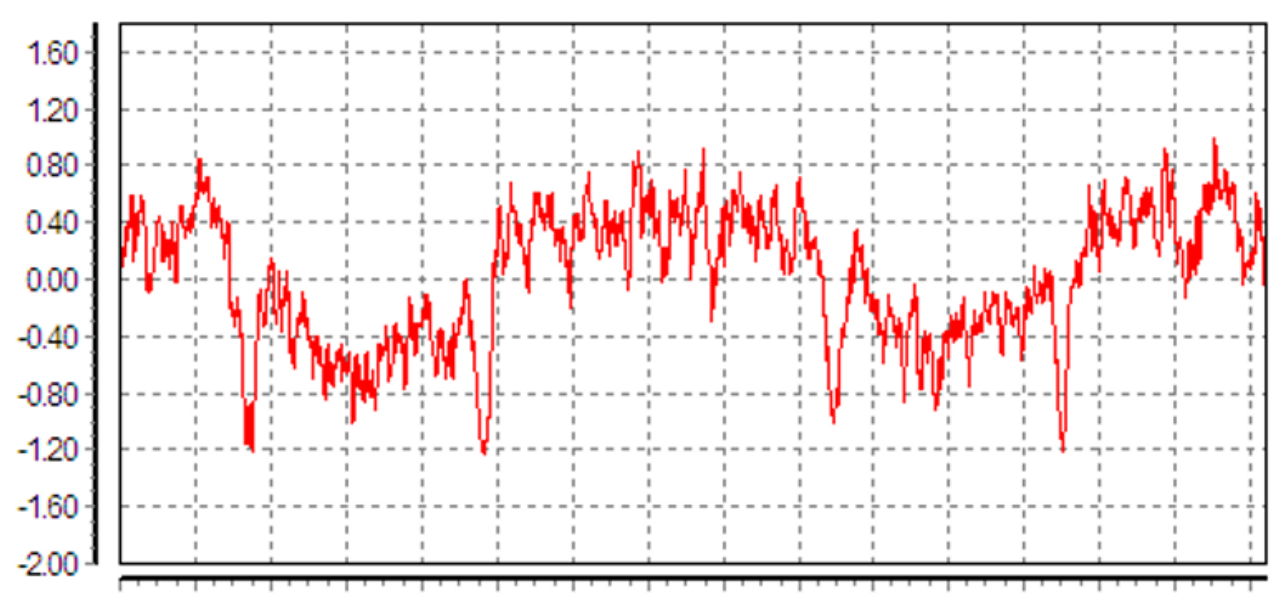

$\bar{v}-10 \# 007$.

0.0000 .2000 .4000 .6000 .8001 .0001 .2001 .4001 .6001 .8002 .0002 .2002 .4002 .6002 .8003 .000

\section{$10^{2}$}

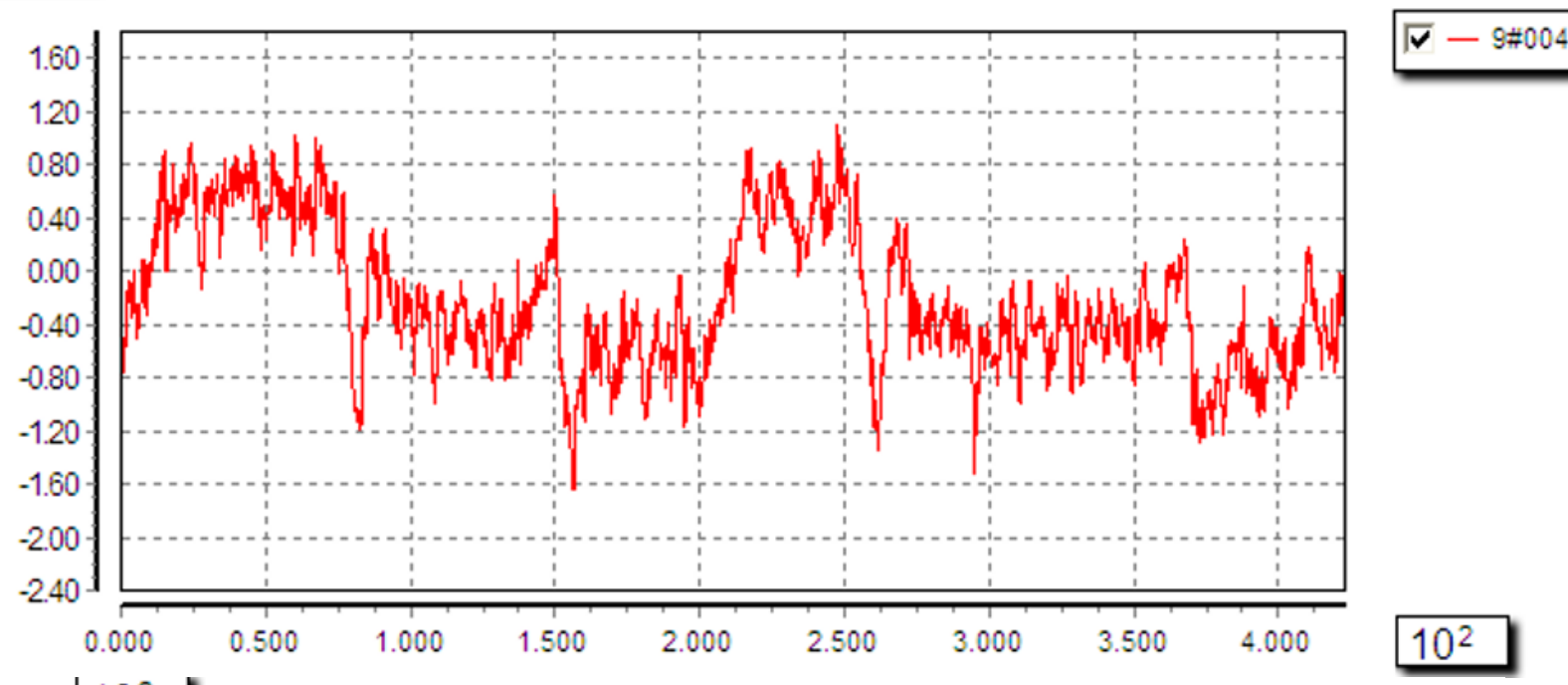
$10^{2}$

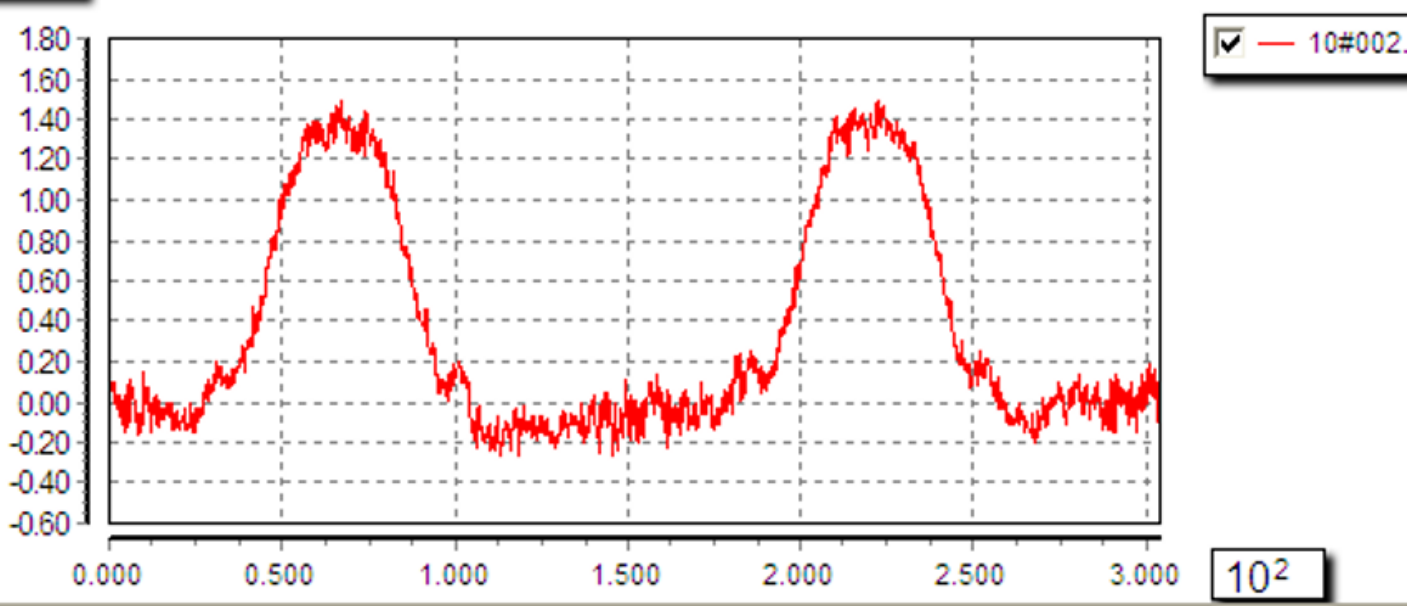

Fig. 2 Stress curve of partial measuring point under dynamic load condition

Table 2 Dynamic stress test result

unit: MPa

\begin{tabular}{|c|c|c|}
\hline $\begin{array}{c}\text { Measuring } \\
\text { point number }\end{array}$ & $\begin{array}{c}\text { Peak value of maximum } \\
\text { dynamic load stress }\end{array}$ & Measuring point position \\
\hline 1 & 127 & The farthest upper cover plate of left front beam \\
\hline 3 & 120 & Front beam pull rod root \\
\hline 5 & 138 & Upper cover plate in the middle of the left front beam pull rod \\
\hline
\end{tabular}




\begin{tabular}{|c|c|c|}
\hline 7 & 110 & Upper cover plate of beam in front of root of hinge point \\
\hline 8 & 97 & Front beam root sea side door frame \\
\hline 10 & 62 & In the middle of the door frame on the rightside of the sea side \\
\hline
\end{tabular}

\section{Nondestructive testing}

According to the evaluation objective, the main welds in the metal structure of the crane and the welds suspected to have defects are tested to determine whether there are internal or surface defects (such as cracks, etc.) in this part. The test results are shown in Table 3.

Table 3 Nondestructive testing results

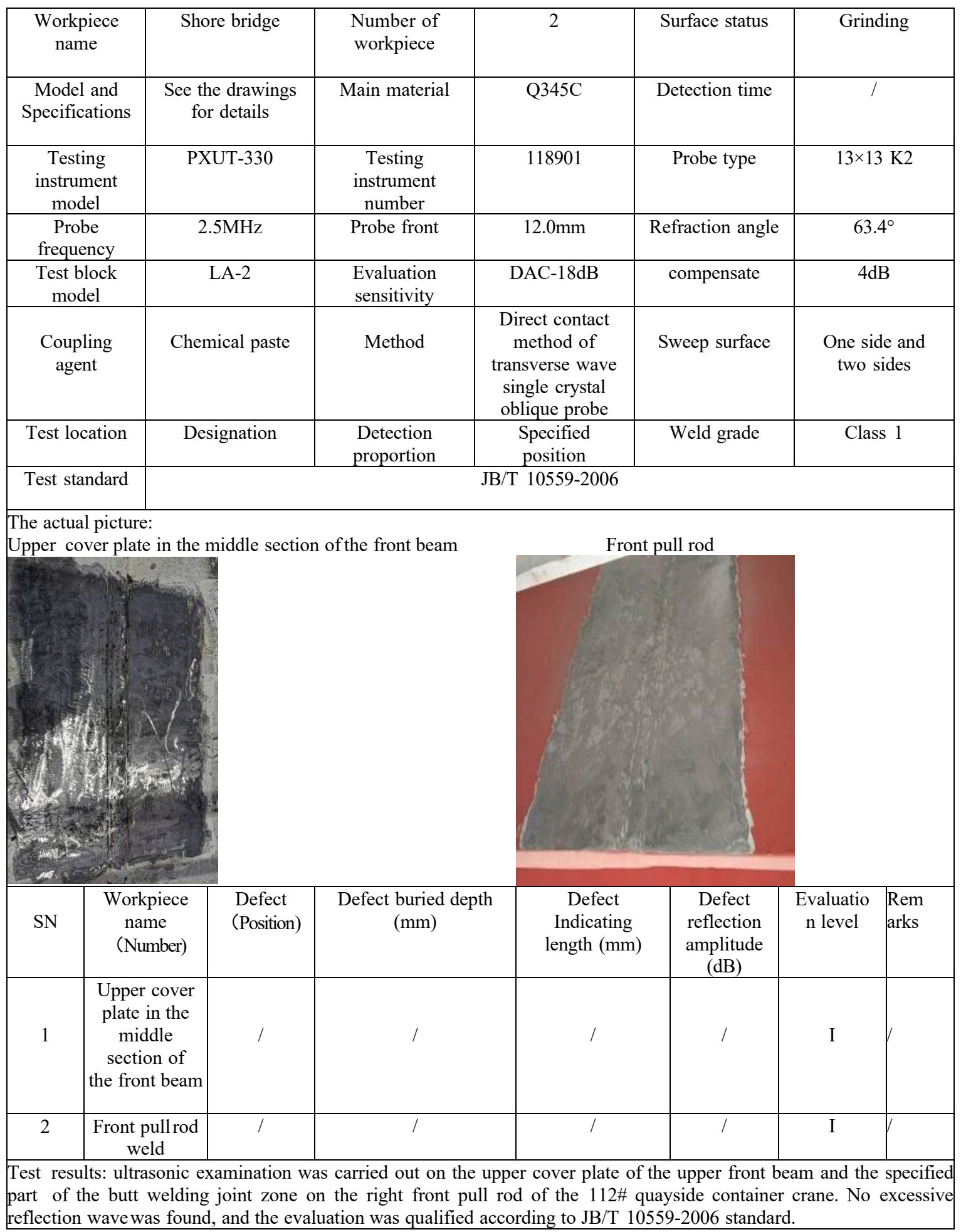




\section{Measurement and result of height difference of trolley track}

A total of 6 measuring points are measured on each track, and the layout of the measuring points is shown in figure 3 . The total station is placed in a suitable position, the coordinates of each measuring point are measured, and the height differences are calculated. The measurement results are shown in Table 4. According to GB/T 10583.1 , the limit value of structural tolerance is $\pm 12.5 \mathrm{~mm}$ and the limit value of running tolerance is $\pm 25 \mathrm{~mm}$. It is found that the height difference of trolley track at the test point is beyond the allowable range of structural tolerance and running tolerance.

Table 4 Test results of track height and difference of trolley

\begin{tabular}{|c|c|c|c|c|c|c|}
\hline $\begin{array}{c}\text { Trolley track } \\
\text { measurement / mm }\end{array}$ & Position1 & Position 2 & Position 3 & Position 4 & Position5 & Position 6 \\
\hline Sea side west & 3974 & 3954 & 3954 & 3933 & 3946 & 3940 \\
\hline Sea side east & 3970 & 3976 & 3954 & 3969 & 3959 & 3967 \\
\hline $\begin{array}{c}\text { Track height } \\
\text { difference }\end{array}$ & 4 & -22 & 0 & -36 & -13 & -27 \\
\hline
\end{tabular}

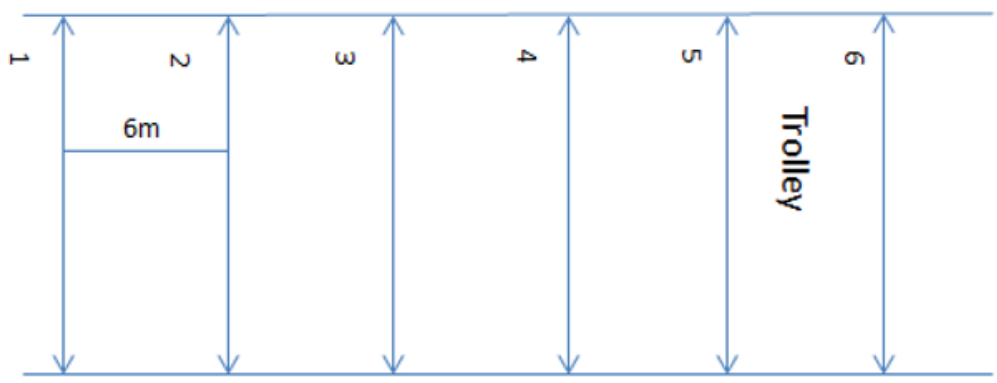

Fig. 3 Schematic diagram of measuring points for height difference of trolley track

\section{Analysis of test results}

After static stress test, the large stress is presented at the measuring points $4 \#$ and 5 in the middle of the front beam. When the trolley with no load is at 1 \# point, the maximum stress value is $42.1 \mathrm{MPA}$, and when the car with rated load is at 1 \# position, the maximum stress of the steel structure of the whole machine is $82 \mathrm{Mpa}$. The yield limit of steel (Q345) selected by the crane is 345 Mpa. According to the relevant regulations in GB3811 $1^{[4]}$, the safety factor of structural strength is 1.34 under the combined load condition, so the allowable stress is $257.46 \mathrm{Mpa}$, and the maximum stress value is $118 \mathrm{Mpa}$ and the safety factor is 2.18 under rated working conditions, which meets the strength requirements of crane steel structure [4].

The dynamic stress test shows that the greater stress is also near the middle of the front beam, the maximum stress value is $138 \mathrm{Mpa}$, and the safety factor is 1.86 . Although the peak value of stress at each measuring point does not exceed the allowable stress value of the material, it is close to the allowable stress of the material.

After nondestructive testing, no internal or surface defects (such as cracks, etc.) were found in the spot.

It is found that the height difference of trolley track exceeds the corresponding standard, so it should be repaired to prevent the phenomenon of deviating rail gnawing and to put an end to the occurrence of safety accidents.

\section{Summary}

From the above results, it can be seen that the dangerous part of fatigue is near the middle of the front beam. It is suggested that the daily inspection and maintenance of dangerous parts should be strengthened in the process of use, and the maintenance of connectors and fasteners should be strengthened. Once the problems are found, the problems should be dealt with in time; the height difference of trolley track should be repaired[5].

\section{Referen}

1. Hu Bin. Research status and development trend of stress testing methods [J]. China Special equipment Safety 2016, 31 (12): 1-9

2. Wang Songlei. Application of stress testing Technology in Crane Safety Assessment [J]. China Special equipment Safety, 2011, 27 (11): 22-25

3. Ding Dongfang. Safety performance evaluation of gantry crane based on stress test $[\mathrm{J}]$. Mechanical and Electrical Information 2018, 33 / 74-75

4. Code for crane design: GB/T 3811 [S]

5. Safety code for lifting machinery-part1 :general rules :GB 6067.1/2010[S] 